\section{THE HEWITT MERCURY LAMP AND STATIC CONVERTER.}

$\mathrm{NE}$ of those happy discoveries which at once and unexpectedly supply the solution of a difficult or hopeless problem was brought to the notice of a limited number of railway and of scientific men last Friday evening by Mr. George Westinghouse. The company were invited to meet Mr. Westinghouse at the Westinghouse Company's office in Norfolk Street, Strand, to see two of the inventions of Mr. Peter Cooper Hewitt, of New York, and to meet again at Claridge's Hotel, after an hour, in circumstances that would enable them more easily to contemplate the full beauty of what they had seen.

The mercury vapour lamp consists of a long vacuum tube, perhaps a yard long and an inch in diameter, but of dimensions depending on the current and potential available and the light required, with an electrode at each end, but at the lower end, which is the negative pole, the tube is blown out into a bulb, which contains a quantity of mercury. When the ordinary voltage of a house supply is applied to the terminals, nothing happens at all, as it is not sufficient to break across the long, vacuous gap. If, however, a single spark from an induction coil is sent from one terminal to the other, the current from the house mains is immediately started and continues to pass indefinitely, producing a brilliant light absolutely without flicker, but of a ghastly hue. It is a splendid and economical light, requiring, according to the information furnished, only half a watt, or under favourable conditions only one-third of a watt, to the spherical candle-power, whereas ordinary incandescent lamps require about four watts to the candle-power. It is a beautiful light to work by so long as colour is not a point-for instance, for engineers' drawing or for lathe and machine-shop work-as the extent of the luminous surface does away with the glare and the contrast of sharp shadows cast by lamps of small surface. It is, no doubt, valuable for lots of things, and there is nothing to wear out. But the colour! It is not like the sodium light, practically monochromatic, so that all colour difference is abolished and everything becomes black or yellow or something between the two. That is merely hideous. Here, however, there is plenty of colour. The spectum shows two bright orange lines, a green line, a pale greenish-blue line and a dazzling blue line, but no red. The result is that flowers and coloured articles appear wonderfully coloured, but not with their own natural colours, and what any pigment will look like no one can tell, nor can the faintest idea be formed of what the colour of anything seen by the light of the Hewitt lamp really is. The light plays such pranks with colour that the colour sense seems to have gone crazy. One red thing will appear blue, another black, one blue thing blue, another brown, but the skin becomes ghastly. If anyone sees himself in a glass, it is difficult for him not to form a sort of opinion that he is killed and drowned and dead as well. These effects the Westinghouse people believe may somewhat interfere with the sorccess of the lamp as a domestic luminary. But even here there are possibilities. A wisp of silk dye with a particular crimson dye appears to have its colour enhanced. It shines with a glorious luminosity among its surroundings, on which not a trace of a rosy tone can be discovered. This is a true fluorescence. If a spectroscope be turned on the lamp or any ordinary thing lighted by it, the red end of the spectrum is absent, but when this particular dye is brought up, the whole of the red end flashes out, and other things may be seen more as they are. A striking experiment is to look at the lamp through ruby glass, through which hardly any light can be detected, and then to bring up the dyed silk, which immediately appears to create its own light and shine brilliantly.

NO. I 733, VOL. 67]
Enough has now been said to give an idea of the Hewitt lamp, which is found to have the remarkable property, one not unknown as a vacuum phenomenon, of only allowing a current to pass in one direction, that being with the mercury as a negative pole. If it is attempted to send a common alternating current through a Hewitt lamp, it may be started by a preliminary spark, but at the first reversal it goes out, and so it has to be started perhaps a hundred times a second to keep it going. If, however, the three ends of a star-wound triphase transformer or generator are connected with three electrodes near the top of a globe and the common centre is connected with the mercury pole at the bottom, then, as before, nothing will happen until a starting spark has been sent across the globe, for which purpose a fifth electrode is placed at the top; then at once the triphase current starts running round from electrode to electrode, and always going to the mercury below, and each current being still alive when the next is ready to start, they keep each other going and a single direct current leaves the mercury electrode. By this simple means, it is possible to rectify a current of even Io00 volts, subject, however, to a constant loss of 14 volts in the bulb, and this whatever the voltage. As the contrivance will work with anything between 100 and 1000 yolts, and at present up to 100 amperes, it will be evident that if further experience bears out the information so far available, the present methods of conversion depending on the use of rotary converters and motor generators will be at an end, and the labours and ingenuity of $\mathrm{Mr}$. Pollak and others with the aluminium cell largely superseded. With the higher voltage, the economy is unapproached by other methods, the loss being only $1^{*} 4$ per cent., which appears as heat in the bulb.

C. V. B

\section{THE VIBRATIONS OF GUN BARRELS.}

$A$ SERIES of experiments has been conducted by Messrs. C. Cranz and K. R. Koch for the purpose of obtaining information respecting the character of the vibrations set up in the barrel when a gun is fired. It is a matter of experience that when a cylindrical rod is struck by an approximately axial blow, the particles of the rod, instead of vibrating in straight lines, perform in general elliptic vibrations the axes of which vary in direction at different points, and it was one of the objects of the investigation to ascertain how far a gun barrel behaved in the same manner.

For this purpose, a number of military rifles supplied by the firm of Mauser were furnished with projecting wires the motions of the shadows of which, thrown on a screen by a powerful lens, were recorded by photography, a tuning-fork similarly projected affording a standard of comparison from which the period of vibration could be measured.

The rifles were either fixed in a support of cork or held in the position usually adopted by marksmen, under conditions closely resembling those existing in actual rifle practice. By means of an electric spark, a mark was recorded on the photographic plate indicating the exact instant at which the projectile left the barrel.

An example of the diagrams obtained is shown by Fig. I for a rifle fixed in cork and by Fig. 2 for free firing. It will be observed that under the latter conditions a dark shadow is in general produced by the recoil of the rifle, and it is only possible to study such parts of the vibration curves as are not blotted out by this shadow.

The experiments show that the vibrations are in general, as preclicted, elliptic in character, each vibrating particle describing a small ellipse instead of a straight line. The vibrations are generally similar to those of an elastic rod fixed at one end, and consist of a fundamental t'ine and overtones, of which as many as three have been 
observed. From the tabulated results, it appears that the periods of vibration for the fundamental and first two overtones, while varying considerably for different rifles, may be said to be roughly about $0.04,0.008$ and 0.002 of a second, and the first two overtones are those the periods of which have been the most completely determined. In the case of the other vibrations, most of the tabulated results contain the mere indication that they have been observed, from which it is a natural inference of the reader that they have been much less intense, a result

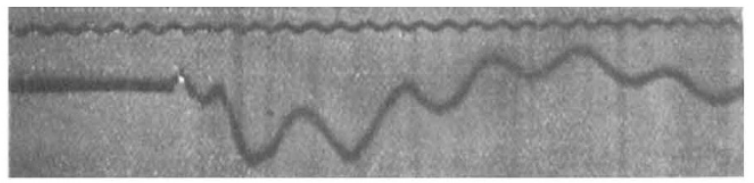

FIG. 1. - 10. Millinetre Servian iflt, right-handed breech, fixed in cork

which appears on general grounds highly probable. The nodal points of the overtone appear to a certain extent to vary periodically in position. The vertex of the angle of vibration, instead of being at the screw of the breech pin, as commonly assumed, is at a nodal point near the muzzle, a result arising fram the effect of one of the overtones at the instant when the bullet leaves the gun, and as the overtones predominate, the vertex approaches the muzzle.

Of practical interest is the conclusion that, since a certain time elapses before the vibrations are completely

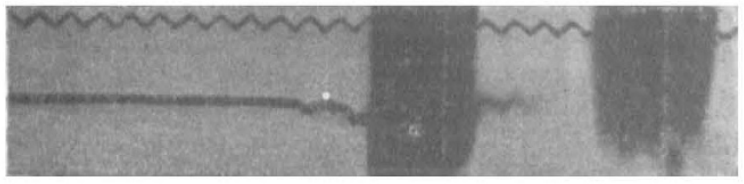

Fıg. 2, $-\mathrm{r} x$-Millimetre Mauser held as in rifle practice. The white spot $\gamma$, indicates the instant of the bullet leaving the barrel.

formed, it is important that the bullet should leave the muzzle before the deflection of the barrel has become considerable, and hence that a small-bore gun is to be preferred to one of large calibre. In the six-millimetre Mauser gun, it would appear, from the position of the white dot in Fig. 3, that the limit in this direction has practically been attained, so far as horizontal vibrations are concerned.

Two further points are discussed. The effect of the breech has been observed by comparing guns with a right-handed and left-handed breech respectively. In

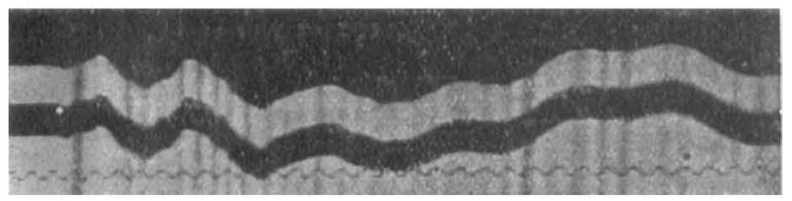

$\gamma$

Fac. 3.-6-Millimetre Mauser rifle, tixed in cork.

the former, a deviation to the right of $7 \mathrm{~mm}$. per 4.5 metres was observed, in the latter, a deviation to the lett of $4 \mathrm{~mm}$. in the same distance.

The other question arises in connection with the attachment of bayonets. In some observations of the horizontal vibrations, a rifle of $1 \mathrm{I} \mathrm{mm}$. calibre was experimented on, with the bayonet attached at one side, the lateral attachment being the best calculated to affect these particular vibrations. The effect was to increase the periods of the first overtone from 0.0095 to 0.0130 of a second and of the second from 0.0016 to 0.0036 of a second, to give rise to a third overtone of period $0.001 \mathrm{I}$ of a second and also to alter the phase at the instant at which the bullet left the muzzle.

The paper of which this is a brief summary is published in the Abhandlungen of the Bavarian Academy (cl. 2, vol. xxi. part iii., pp. 559-574), and it will be seen that it has an important bearing on rifle shooting generally. A marksman who is fully aware of the nature of the vibrations occurring in his rifle ought to be able to allow for them, with a little practice, far better than one ignorant of the scientific aspect of the question.

\section{(i. H. BRYAN}

\section{PROF. JOHN YOUNG.}

OHN YOUNG was born in Edinburgh in 1835. He was educated at the High School and at the University, and finally he graduated as doctor of medicine. Like many of his time, he came under the spell of the great teachers who then made the northern university famous, such men as Goodsir, Edward Forbes, Christison, Syme and Sinipson, and there is reason to believe that in particular the first two gave a scientific bias to $\mathrm{Dr}$. Young's career. For some time he worked on the staff of the Ordnance Survey and made a friend of Sir Roderick Murchison, then a leader in the geological world. This was followed by his appointnient to the chair of natural history in the University of Glasgow in 1866, and in this chair he taught both zoology and geology for nearly thirty-five years. After a period of failing health, he died on December 13,1902. Such, in brief, is an outline of his career, but those who knew Dr. Young will recognise how imperfect a representation it is of the man's personality. Gifted with a keen and penetrating intellect and a fertile imagination, showing versatility of acquirements rarely met with, absolutely unconventional, he was also a man of untiring and restless energy. He was a scholar in a high sense of the term, he possessed a cultivated and pure literary taste, he was an artist facile both with brush and pencil, and he had a wide and critical taste in music. As keeper of the Hunterian Museum, he acquired much knowledge of rare books and manuscripts, of the great collection of coins and medals to be found there, and of works of art. Wide, however, as was the sphere of his activity in the University, he yet found time for active labours in the cause of female education, in the work of the Technical College, and in the municipal and social life of the city of Glasgow. It was this versatility and superabundant energy that hindered Dr. Young from doing the amount of original work in the two sciences of zoology and geology which might have been expected from a man of his genius, and the work of his life must not be judged from this point of view. His chief labour, perhaps, was the systematic arrangement of the great legacy of IVilliam Hunter-books, pictures, medals, engravings, coins-and in this work he took a keen delight and over it he spent laborious hours, even far on into the night when silence reigned in the cloisters. But it was the man's individuality of character that made him a force in his time. Often a determined opponent, he could also be a true friend, while his mental monds, sometimes quiet and observant, ofttimes brilliant and radiant with flashes of wit and humnur, constrained even those who knew him best to regard him as a man quite by himself. He has thus left little of an enduring character in the literature of science, but he will be long remembered by many generations of students in the University of Glasgow.

JOHN G. MCKENDRICK.

NO. 1733 , voL. 67] 